\title{
WRITTEN ASSIGNMENTS, UNDERGRADUATE LEVELS OF CONFIDENCE AND THE ENGINEERING PORTFOLIO
}

\author{
Anne Parker and Kathryn Marcynuk, Vanier Scholar \\ Centre for Engineering Professional Practice and Engineering Education \\ University of Manitoba \\ Anne.Parker@umanitoba.ca; ummarcyk@,cc.umanitoba.ca
}

\begin{abstract}
In this paper, we will summarize some of the results, first, from our course syllabi project that we conducted at the University of Manitoba and, secondly, from our study of second-year students' levels of confidence in a communication class. In the course syllabi project, we discovered that course outlines in our Engineering school gave little information on the assignments expected of students, so much so that students may have found completing them to be difficult. In the second study, we found that students generally lacked confidence in writing tasks, especially at the beginning of term. These two studies suggest that we need to find a way to guide students in the writing of the assignments that we expect of them if they are to develop the necessary confidence in their ability to write well within a professional context.

One way to do that may be the introduction of a portfolio requirement within the Engineering curriculum, A portfolio will serve as a record of students' ongoing achievements in written assignments throughout their academic programs and, as they compile their portfolios, they can reflect on that achievement and move forward more communicatively competent and more confident.
\end{abstract}

Keywords: writing assignments, self-efficacy, communication skills and Attribute 7, undergraduate engineering education, lifelong learning

\section{INTRODUCTION}

This paper originated in two projects [5]. [6]. One project, the analysis of course syllabi in the Faculty of Engineering at the University of Manitoba, was part of a national study looking into the kinds of writing assignments that we require our students to complete. At the University of Manitoba, we collected syllabi for 133 courses; of these, we analyzed 98 course syllabi (47 from Electrical and Computer Engineering, 37 from Mechanical Engineering and 14 from Civil Engineering) and, while the reported number of writing assignments understandably differed from department to department, the trends between departments were remarkably similar.

The second study was restricted to our second-year communication class. From 2013-2015, we asked 450 students to self-report on their levels of confidence in four critical areas of communication - writing, speaking, teamwork and personal skills development (or lifelong learning). Similar to other researchers' practice [7], the surveys were anonymous and students self-reported on each item. In this way, students could respond as honestly as possible to each query; no individual marks or course outcomes were attached to the individuals who participated in the surveys.

As expected, students expressed the least confidence in their writing and speaking skills at the beginning of the year (when we conducted our first survey); in the second survey, conducted at the end of the semester, 378 students responded that these confidence levels had increased after they had the chance to learn more about writing within the professional context. What's more, they had had the chance to practice writing and develop some successful strategies of their own over the term.

\section{THE COURSE SYLLABI PROJECT}

This project was part of a national study on writing across the curriculum (WAC). Originating at the University of Alberta under the direction of Dr. Roger Graves, the study was comprised of 11 institutions and more than 36 departments, including liberal arts, service learning, nursing and Engineering. The objective of the study was to do a systematic investigation into the writing demands that are placed on undergraduate students in these various disciplines; we would then map these demands so that we could develop a "program profile" for each academic unit [1]. Ultimately, these program profiles would encourage departments and faculties to begin further discussions on the way writing is taught and supported within the discipline. 
For this study, in order to track which courses did, in fact, include written assignments, we considered only those course outlines that included Attribute 7, "Communication Skills," on the course outline. However, because of the lack of detail on the nature and extent of the writing involved in any written assignments, we necessarily had to assume that, unless stated otherwise, these courses contained at least some writing components.

Of the 98 outlines that identified Attribute 7, Civil Engineering (CE) had the fewest (14 course syllabi) while Mechanical Engineering (ME) had 37 and Electrical and Computer Engineering (ECE) had 47 course syllabi identifying Attribute 7. Even more interesting, though, is the total number of assignments indicated by each department: 33 in CE, 87 in ECE and 105 in ME. Of particular note here is the average number of written assignments in each successive year increases.

\section{Total Number of Written Assignments by Year}

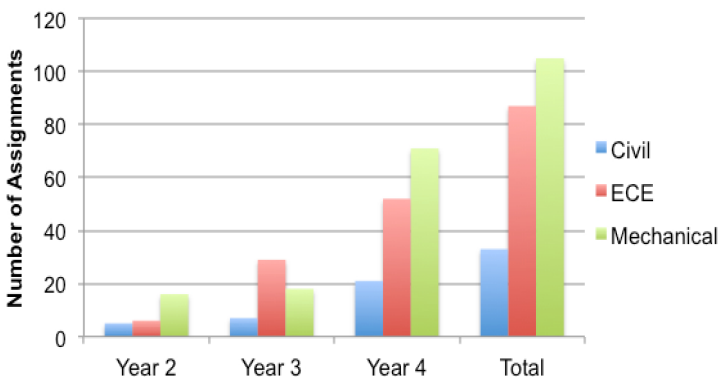

Fig.1. Total number of written assignments by year

Only ECE requires more assignments in the $2^{\text {nd }}$ year; otherwise, the number of assignments required increases in both $\mathrm{CE}$ and $\mathrm{ME}$.

Figure 2 shows the average number of written assignments required for each course.

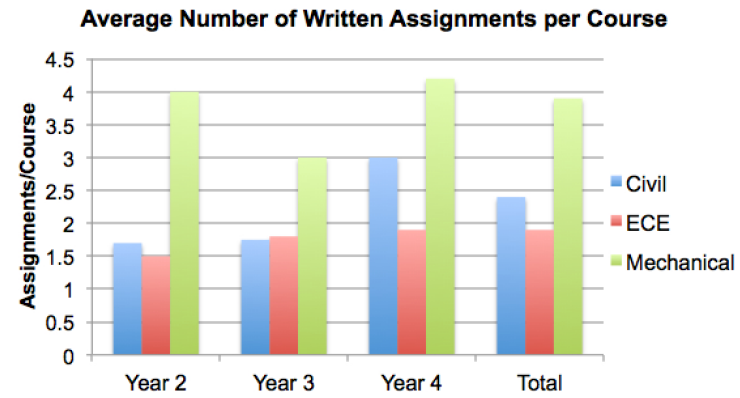

Fig. 2. Average Number of Written Assignments per Course

ECE required 1.9 written assignments per course, on average, while $\mathrm{CE}$ required 2.4 written assignments per course and ME required the most written assignments, 3.9 per course.
In Figure 3 below, the first number is the total number of assignments in each year of the discipline while the second number is the average number of assignments per course.

\begin{tabular}{|llll|}
\hline & Civil & Electrical & Mechanical \\
\hline Year $\mathbf{2}$ & $5 / 1.7$ & $6 / 1.5$ & $16 / 4$ \\
\hline Year 3 & $7 / 1.75$ & $29 / 1.8$ & $18 / 3$ \\
\hline Year 4 & $21 / 3$ & $52 / 1.9$ & $71 / 4.2$ \\
\hline
\end{tabular}

Fig. 3. Average number of assignments per course per year

Although Engineering has fewer overall written assignments, the average number of assignments per course per year does reflect the general trends found in the national study: as a student progresses through a program, the demand for writing assignments does indeed increase.

Notwithstanding these findings, in our study they are more suggestive than definitive. What they tell us is Engineering does include written components, at least in some measure. In most cases, however, the course syllabi we collected omitted important information about these written assignments so that students would not know what the expected length was to be, or how the assignment would be evaluated, or even the assignment's engineering genre. While not an uncommon problem in most course outlines [3], this singular lack of "prompts" to guide students' writing might well cause them to falter in its completion, especially for those students who lack confidence in their ability to write well.

\section{THE STUDY ON SELF-REPORTED LEVELS OF CONFIDENCE AND PROFICIENCY}

This study involved two surveys conducted from 2013-2015 in a second-year Technical Communication class, administered in the first class for the first one and at the last class for the second one. The goal was to determine the levels of confidence these students felt when it came to a variety of communication tasks that we routinely ask them to do in the class, such as working on a team, delivering a speech to the class or writing a shorter document $(<5 \mathrm{pp})$. We ask them to indicate how confident they are right now and to use a scale from $1-5$, where 1 is not confident, 3 is confident and 5 is very confident. They use this scale for all 20 questions and in all four areas of writing, 
speaking, teamwork and personal skills development (lifelong learning).

The second survey asks the same 20 questions in the same four areas, but we also ask them to indicate their current level of proficiency in each area as well as the expected level once they graduate. These proficiency levels, based on CDIO's scale [2], range from 1, "having experience" (or been exposed to); to 2, "able to participate in and contribute to"; to 3, "being able to understand and explain"; to 4, "skilled in the practice or implementation of"; to 5 "able to lead or innovate in."

Figure 4, which shows the results for the winter terms (W), summer terms (S) and fall terms (F) from 2013-2015, gives the responses to the first item on writing: "Writing a short document ( $<5$ pp.) for an Engineering audience."

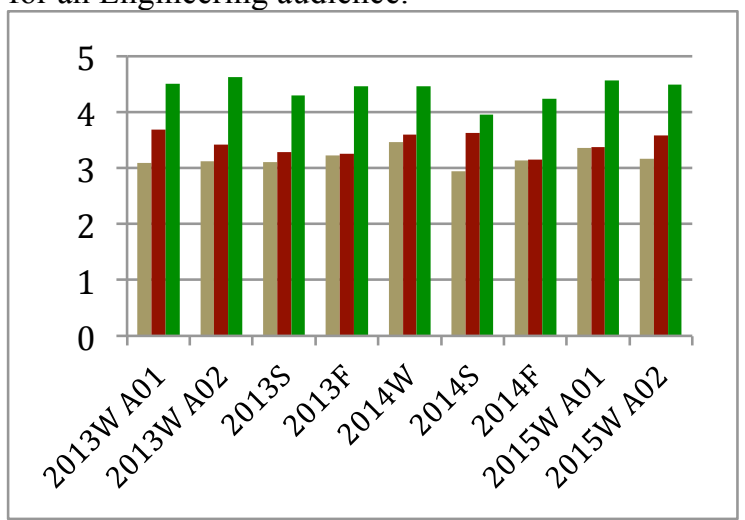

Fig. 4. Writing Skills Survey Responses (Q.1)

The tan bar represents Survey 1, the red bar Survey 2 , and the green bar the expected proficiency level at graduation. Here, the Survey 1 average is 3.18 while the Survey 2 average is 3.44 ; the graduation average, however, is considerably higher, 4.40 .

Figure 5, which shows the results for the fall, winter and summer terms for 2013-2015, gives the responses for question 3: "Writing a short document for a non-Engineering audience."

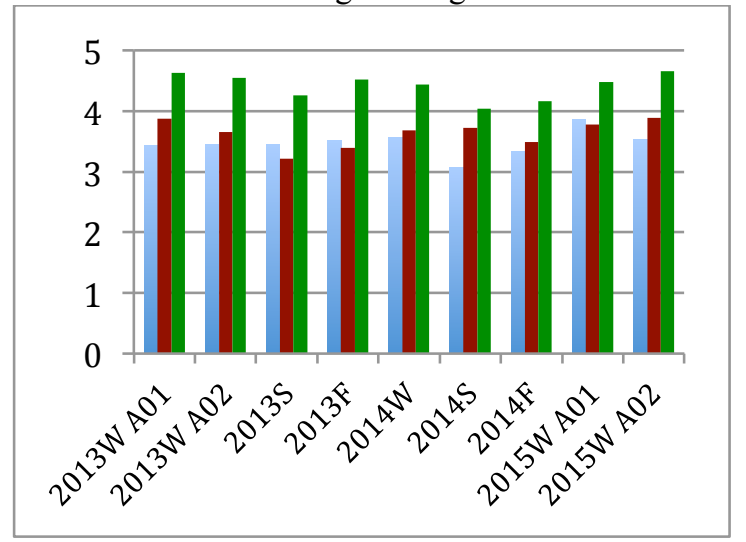

Fig. 5. Writing Skills Survey Responses (Q.3)
Interestingly, students would feel slightly less confident addressing a short document to a nonspecialist audience, presumably because they would have to be far more careful about language, structure and even appropriate graphics. In the first survey, shown in blue, the average was 3.47 while the average for the second survey, shown in red, was 3.63. As expected, the graduation average is higher, 4.42, shown in green.

These results indicate that students in general feel they have attained a level of proficiency once they have completed most communication tasks successfully, even though they believe that they have much more to do if they are to match what they believe are the expectations of them when they graduate. One way to bolster their confidence levels may be asking them to collect all their written work into a portfolio.

\section{CONCLUSION: WRITTEN ASSIGNMENTS, LEVELS OF CONFIDENCE AND THE ENGINEERING PORTFOLIO}

Tracking performance and confidence levels over time has proven to be difficult, particularly when it comes to writing. So much so that we now suspect that there may be a real disconnect between what we expect our students to do in their written assignments and what they feel confident in doing. Given the number of assignments students may be required to write in their Engineering program, especially in their graduating year, and given the proficiency levels students feel they are expected to achieve by their graduating year, we need a way to bridge the gap between confidence and performance. As others have suggested, a belief in one's ability to do a task enhances one's ability to actually perform it [4], [8].

What we have found in these two projects, both the study of written assignments and the study of undergraduate levels of confidence, has led us to believe that many students may need tangible evidence of their growth and achievements as writers. Grades are certainly one measure, but, first and foremost, writing is a process that develops with practice and over time; all the steps in the process are inter-connected, such that together they form an identifiable outcome [6]. Grades are one outcome, to be sure, but they reflect an outcome only at that moment and at that level of proficiency; put another way, grades reflect where a student currently is in the process. Paretti puts it even more eloquently: "writing is not a skill learned once and then repeated forever, like scales on a piano"; rather, "every act of 
communication is like a new musical piece" that will demand practice [7].

On another level, compounding the problem is the C.E.A.B.'s insistence that we demonstrate that we do what we say we do and that we can substantiate our claim that our graduating students are now communicatively competent; that is, they are proficient in communicating the engineering work graphically, orally and in writing. To that end, we are now looking at the possibility of suggesting that an Engineering portfolio be introduced into the Engineering program. A portfolio would showcase a student's achievements over time while also documenting them.

We have more work to do on this initiative, to be sure, but we are thinking that an ongoing collection of a student's written work is a good start. A portfolio may be a way to demonstrate progressive changes and development of the writing over time, not just in one year of study, but over several years. It becomes a timeline of a student's progress in Engineering. The important thing is to have students collect first and sort later; doing so provides them with valuable experience in documenting their work as they go and, just as importantly, reflecting on where they've been and where they're going.

However, in addition to bolstering their levels of confidence, a portfolio may also be a way to bridge the gap between the engineering work and the communication of it. For graduating students, a portfolio would serve to showcase their Engineering design work and serve to demonstrate their growth both as communicators and as engineers. For all the stakeholders - students, faculty and industry - the portfolio may well serve as an example of our combined success.

\section{Acknowledgements}

The study of undergraduate written assignments has been made possible by a grant from the Social Sciences and Humanities Research Council of Canada (SRG RES0006514). We would also like to acknowledge Dr. Roger Graves, Professor, English and Film Studies and Director, Writing Across the Curriculum, University of Alberta.

\section{References}

[1] Anson, Chris A. and Deanna Dannels, "Profiling programs: Formative uses of departmental consultations in the assessment of communication across the curriculum," Across the Disciplines: A Journal of Language, Learning and Academic Writing [Online], 6 [Special Issue on Communication across the Engineering Curriculum], v.3, no.2, pp. 1-16, 2009 (Dec.). Available: http://wac.colostate.ediu/atd/assessmenet/anson dannels.c fm [Accessed May 22, 2012]

[2] CDIO (Conceiving, Designing, Implementing, Operating], "3. Determining the appropriate levels of student proficiency for syllabus topics," 2008. Available: www.cdoio.org/files/syllabus pt.3.pdf. [Accessed May 4, 2015]

[3] Graves, Roger, Theresa Hyland and Boba Samuels, "Undergraduate writing assignments: An analysis of syllabi at one CCanadian college," Written Communication, v.27, n.3, pp. 293-317, 2010.

[4] Mamaril, Natasha A., Ellen L. Usher, Caihong R. Li, D. Ross economy and Marian S. Kennedy, "Measuring undergraduate students' Engineering self-efficacy: A validation study," Journal of Engineering Education, v.105, n.2, pp. 366-395, 2016 (April).

[5] Parker, Anne and Kathryn Marcynuk, "Undergraduate writing assignments in Engineering: Targeting communication skills (Attribute 7)," Canadian Engineering Education Conf. CEEA16 (Dalhousie University, Halifax, N.S., June 19-22, 2016), 5pp, 2016.

[6] Parker, Anne and Kathryn Marcynuk, "The selfreported confidence and proficiency levels of undergraduate Engineering students in an Engineering Technical Communication course," Canadian Engineering Education Conf. CEEA15 (McMaster University, Hamilton, Ont., 2015), 5pp, 2015.

[7] Paretti, Marie C., "Communication as professional practice: Designing assignments to develop Engineering professionals," ASSEE Southeast Conference (The University of Tennessee at Chattanooga, April 3-5, 2005), 10 pp., 2005.

[8] Shoemaker, Candice A, "Student confidence as a measure of learning in an undergraduate Principles of Horticultural Science course," HortTechnology, August 2010, v.20, n.4, pp. 683-688, 2010. 